\title{
Native Oxide Layers Formed on the Surface of Ultra High-Purity Iron and Copper Investigated by Angle Resolved XPS
}

\author{
S. Suzuki ${ }^{\dagger}$, Y. Ishikawa, M. Isshiki and Y. Waseda \\ Institute for Advanced Materials Processing, Tohoku University, \\ 2-2-1 Katahira, Aoba-ku, Sendai 980-77, Japan
}

\begin{abstract}
Angle resolved X-ray photoelectron spectroscopy (AR-XPS) has been used for characterizing native oxide layers formed on the surface of ultra high-purity iron and copper by exposure to air at room temperature. Thickness of an oxide layer formed on the surface of ultra high-purity iron is found to be thicker than that for ultra high-purity copper in the initial stage of oxidation and almost unchanged by air exposure time. On the other hand, thickness of an oxide layer formed on ultra high-purity copper is found to increase with increasing air exposure time. These results are consistent with spectral information for ultra high-purity iron and copper exposed to air; the chemical state of $\mathrm{Fe}$ in the surface of ultra high-purity iron is almost independent of exposure time, whereas the chemical state varies in the surface of ultra high-purity copper by exposure for a long term.
\end{abstract}

(Received February 25, 1997)

Keywords: ultra high-purity iron, ultra high-purity copper, angle resolved X-ray photoelectron spectroscopy, initial oxidation

\section{Introduction}

High-purity materials sometimes demonstrate prominent properties compared to less pure materials. For instance, ultra high-purity iron prepared by the ion exchange and zone refining technique ${ }^{(1)}$ was found to show very low corrosion rate in acid aqueous solutions ${ }^{(2)}$. Therefore, ultra high-purity iron is considered to be one of the promising materials for corrosion-resident thin films when deposited on silicon wafer ${ }^{(3)}$. On the other hand, the preparation method of high-purity copper based on the floating zone refining was also developed ${ }^{(4)}$. Since the electrical conductivity of such ultra high-purity copper is much higher than that of aluminum, it is considered to be useful the application to high density electronic devices.

Such ultra high-purity base metals indicate potential for creating new technology, so that characterization of their intrinsic properties is strongly required. This includes characteristic features of a native oxide layer formed on the surface of ultra high-purity metals during air exposure, because it is likely to strongly affect their total performance. So far the effect of exposure of low partial pressure of oxygen on the surface state has been reported in high-purity iron ${ }^{(5)}$ and copper ${ }^{(6)(7)}$ of commercial grade. Although native oxide layers on the surface of a few kinds of high-purity iron have been studied ${ }^{(8)}$, systematic information about native oxide layers sequentially grown on the surface of different ultra high-purity

$\dagger$ Present address: Advanced Technology Research Laboratories, Nippon Steel Corporation, Ida, Nakahara-ku, Kawasaki 211, Japan. metals has not been characterized.

Recently, the present authors have investigated native oxide layers formed on the iron-chromium binary alloys at room temperature using angle resolved X-ray photoelectron spectroscopy (AR-XPS) ${ }^{(9)-(11)}$, and found systematic change in thickness of oxide layers by the surface chromium concentration. Furthermore, AR-XPS is recognized as a reliable tool for non-destructive analysis by obtaining a change of the surface state of metals. These prompt us to extend the AR-XPS method to native oxide layers formed on the surface of ultra high-purity iron and copper by air exposure using AR-XPS.

\section{Experimental}

Ultra high-purity iron and copper were produced by the zone refining method, which has already been described in detail ${ }^{(1)(4)}$ and not duplicated here. Specimens were cold rolled to $0.5 \mathrm{~mm}$ thick plates, and the plates were cut to about $10 \mathrm{~mm}$ square and annealed in hydrogen gas. They were electrolytically polished, and the residual resistivity ratio of ultra high-purity iron and copper prepared by this method ${ }^{(1)(4)}$ was confirmed to be the order of about $1 \times 10^{4}$ and $3 \times 10^{4}$, respectively.

A pair of ultra high-purity iron and copper plates were mounted onto a specimen holder, in order to compare native oxide layers formed on their surface under given conditions. The specimen surface was cleaned by argon ion sputtering operated at $3 \mathrm{kV}$ in an XPS spectrometer under ultra high vacuum before air exposure, to obtain the contamination-free surface. After cleaning, the pair of ultra high-purity iron and copper plates were simultaneously exposed to air at $298 \mathrm{~K}$ for a period from $6 \times 10^{2} \mathrm{~s}$ 
to $1 \times 10^{6} \mathrm{~s}$. Native oxide layers in each exposure step were characterized by XPS while interrupting air exposure.

XPS measurements were carried out in the same manner of the previous work ${ }^{(9)}$. Only some essential points are given below. An XPS apparatus (PHI-5600) with a computer aided tilting stage was used, and the incident $\mathrm{X}$-ray was monochromated $\mathrm{Al} K \alpha$ radiation. $\mathrm{Fe} 2 \mathrm{p}, \mathrm{Cu}$ $2 \mathrm{p}, \mathrm{O} 1 \mathrm{~s}$ and $\mathrm{C} 1 \mathrm{~s}$ XPS spectra were recorded, and their relative sensitivity factors were used for quantification. The take-off angle corresponding to the angle between the direction of an analyzer and the specimen plane, was changed from $0.262 \mathrm{rad}$ (15 degree) to $1.31 \mathrm{rad}$ (75 degree) in the AR-XPS measurements. In addition, angle resolved X-ray excited Auger electron spectra (ARXAES) for copper were recorded to study the chemical state of copper ${ }^{(12)}$, since the chemical shift of $\mathrm{Cu} 2 \mathrm{p}$ XPS spectra is very small between $\mathrm{Cu}^{0}$ and $\mathrm{Cu}^{1+}$.

In order to discuss the thickness of the surface layers of specimens quantitatively, the concentration corresponding to a relative XPS signal for constituent elements is estimated, by coupling with a layered structure model $^{(9)}$. Two layers of a contaminated layer consisting of mostly hydrocarbon, that is aliphatic carbon, and an oxidized layer are expressed by the model. Intensities for all constituent elements are analyzed in this work $^{(9)}$; by comparing the intensities for these layered structures to the relationship between the concentration and take-off angle for each element, the effective thickness of the overlayer and oxide layer can be estimated ${ }^{(9)}$. The compositions of the contaminated layer and the oxide layer was assumed along the way similar to the previous work $^{(9)}$, using the inelastic mean free path of electrons in the layers $^{(13)(14)}$.

\section{Results and Discussion}

\section{XPS spectra}

\section{(1) Ultra high-purity iron}

Figure 1(a)-(e) shows Fe 2p AR-XPS spectra obtained in the take-off angle from $0.262 \mathrm{rad}$ ( 15 degree) to 1.31 rad (75 degree) by a step of 0.262 rad for ultra high-purity iron which was exposed to air for $1.8 \times 10^{3} \mathrm{~s}$. Fe $2 \mathrm{p}$ AR-XPS spectra for ultra high-purity iron exposed to air for $4.2 \times 10^{5} \mathrm{~s}$ are also shown in Fig. 2. In these figures, the spectra of $\mathrm{Fe} 2 \mathrm{p}$ for a specimen exposed to air can be allocated to the signals from $\mathrm{Fe}$ oxide (major $\mathrm{Fe}^{3+}(\mathrm{Fe}$ $\left.2 \mathrm{p}_{3 / 2}: 710.9 \mathrm{eV} ; 1 \mathrm{eV}=1.6 \times 10^{-19} \mathrm{~J}\right)$ oxide and minor $\mathrm{Fe}^{2+}\left(\mathrm{Fe} \mathrm{2} \mathrm{p}_{3 / 2}: 709.4 \mathrm{eV}\right)$ oxide in this case), and metallic iron $\left(\mathrm{Fe}^{0}\left(\mathrm{Fe} 2 \mathrm{p}_{3 / 2}: 707.0 \mathrm{eV}\right)\right)$. It is stressed in both figures that a peak due to metallic iron of $\mathrm{Fe}^{0}$ is recognized well when increasing take-off angle from (a) to (e). Thus result clearly indicates that an oxide layer covers the metallic iron surface, of which thickness is comparable to the inelastic mean free path of X-ray photoelectrons. However, by comparing the relative intensities of the oxide peaks to the metallic peaks in $\mathrm{Fe} 2 \mathrm{p}$ spectra given in Figs. 1 and 2, spectral variation corresponding to the

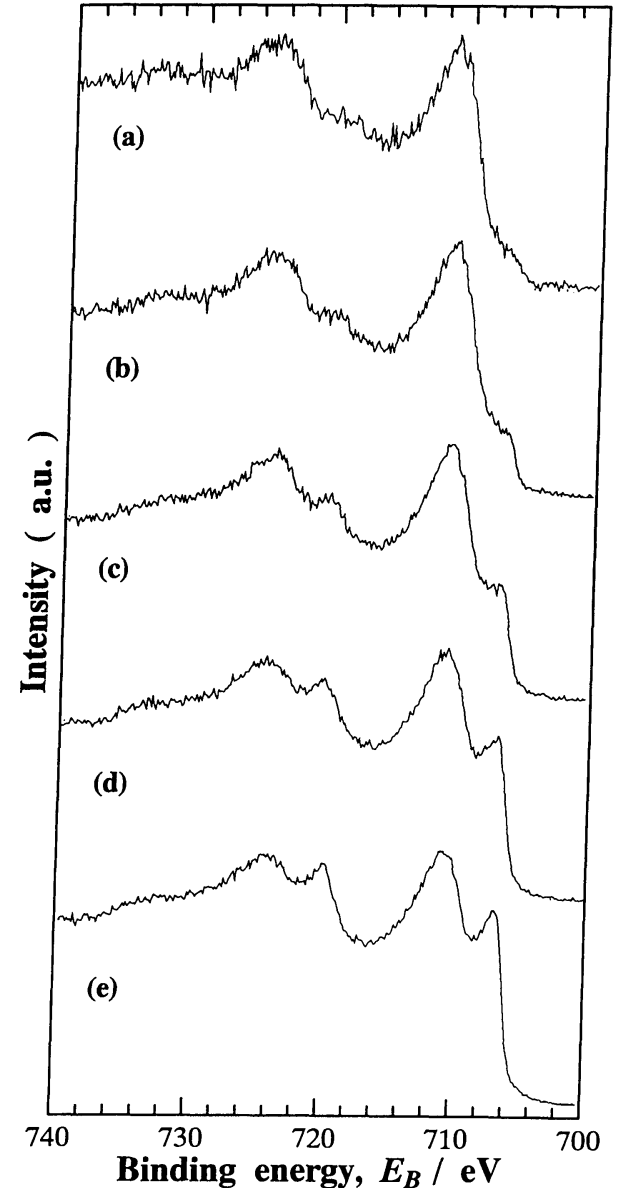

Fig. 1 Fe 2p AR-XPS spectra obtained in the take-off angle of (a) $0.262 \mathrm{rad}$, (b) $0.524 \mathrm{rad}$, (c) $0.786 \mathrm{rad}$, (d) $1.05 \mathrm{rad}$ and (e) $1.31 \mathrm{rad}$ for ultra high-purity iron exposed to air for $1.8 \times 10^{3} \mathrm{~s}$.

chemical change of the surface of ultra high-purity iron, is found to be almost insensitive to time for exposure of air, although a difference of exposure time is of two order of magnitude.

\section{(2) Ultra high-purity copper}

Figure 3 shows $\mathrm{Cu} 2 \mathrm{p}$ AR-XPS spectra for ultra highpurity copper which was exposed to air for $1.8 \times 10^{3} \mathrm{~s}$. Although any significant take-off angle dependence is not clearly observed in these $\mathrm{Cu} 2 \mathrm{p}$ AR-XPS spectra, the present authors maintain the view that this results from a very small difference of the peak position between a

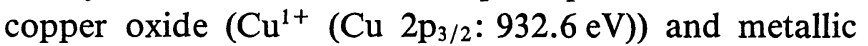
copper $\left(\mathrm{Cu}^{0}\left(\mathrm{Cu} 2 \mathrm{p}_{3 / 2}: 932.7 \mathrm{eV}\right)\right)$. Since $\mathrm{Cu}$ LMM AES spectra are often used for detecting the chemical state of copper oxides ${ }^{(12)}, \mathrm{Cu} \mathrm{L}_{3} \mathrm{M}_{45} \mathrm{M}_{45}$ AR-XAES spectra for ultra high-purity copper exposed to air for $1.8 \times 10^{3} \mathrm{~s}$ were measured and the results were given in Fig. 4 where spectral intensities are plotted as a function of the electron kinetic energy. The spectra of $\mathrm{Cu} \mathrm{L}_{3} \mathrm{M}_{45} \mathrm{M}_{45} \mathrm{AR}-$ XAES for this specimen could be assigned to the signals from a copper oxide $\left(\mathrm{Cu}^{1+}\left(\mathrm{Cu} \mathrm{2} \mathrm{p}_{3 / 2}: 916.2 \mathrm{eV}\right)\right)$, and metallic copper $\left(\mathrm{Cu}^{0}\left(\mathrm{Cu} 2 \mathrm{p}_{3 / 2}: 918.6 \mathrm{eV}\right)\right)^{(15)}$. In the results of Fig. 4, a peak due to $\mathrm{Cu}^{0}$ appears to increase 


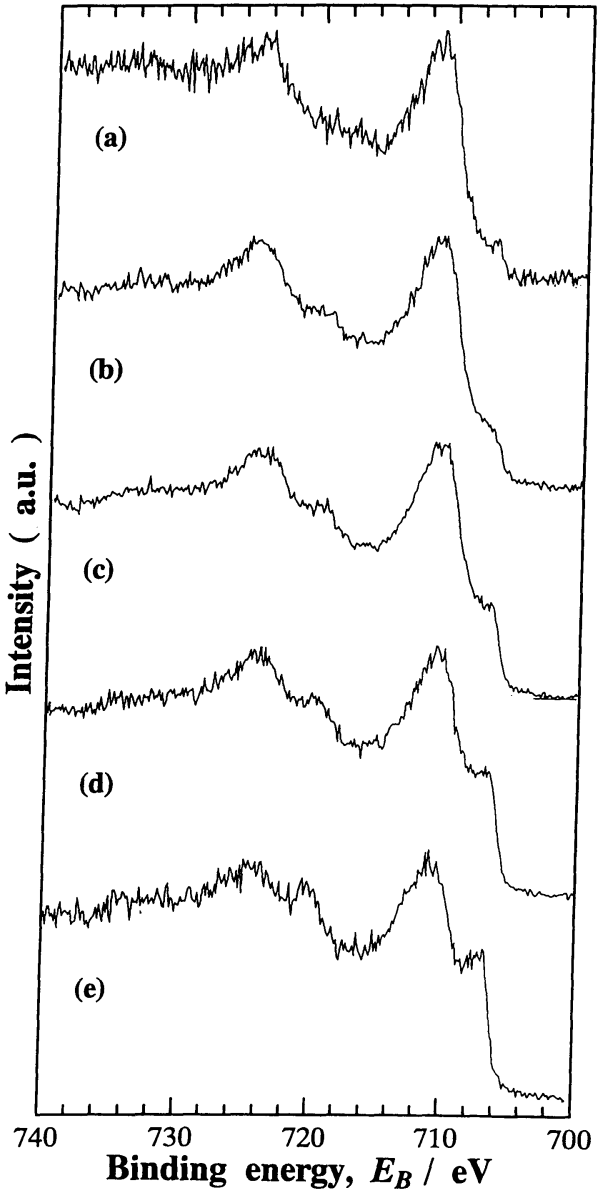

Fig. 2 Fe 2p AR-XPS spectra obtained in the take-off angle of (a) $0.262 \mathrm{rad}$, (b) $0.524 \mathrm{rad}$, (c) $0.786 \mathrm{rad}$, (d) $1.05 \mathrm{rad}$ and (e) $1.31 \mathrm{rad}$ for ultra high-purity iron exposed to air for $4.2 \times 10^{5} \mathrm{~s}$.

with increasing take-off angle, just as results obtained by AR-XPS for the iron case, and then it may safely be said that an oxide layer with $\mathrm{Cu}^{1+}$ covers the metallic copper surface.

On the other hand, Fig. 5 shows Cu 2p AR-XPS spectra for ultra high-purity copper which was exposed to air for $4.2 \times 10^{5} \mathrm{~s}$. An additional peak, which can be assigned to $\mathrm{Cu}^{2+}\left(\mathrm{Cu} 2 \mathrm{p}_{3 / 2}: 935.6 \mathrm{eV}\right)$, appears by this long term exposure of $4.2 \times 10^{5} \mathrm{~s}$. The take-off angle dependence of the peak intensity of $\mathrm{Cu}^{2+}$ that an oxide layer with $\mathrm{Cu}^{2+}$ covers the copper substrate as well as the oxide layer with $\mathrm{Cu}^{1+}$. These results imply that the long term air exposure induces the chemical change of the specimen surface of ultra high-purity copper, and this feature contrasts with the case for ultra high-purity iron.

\section{Thickness of oxide and contaminated films}

Figures 6(a) and (b) show the values of concentration of iron, oxygen and carbon estimated from measured AR-XPS intensity data for ultra high-purity iron specimens exposed to air for $1.8 \times 10^{3} \mathrm{~s}$ and $4.2 \times 10^{5} \mathrm{~s}$ is plotted as marks as a function of take-off angle, respectively. The monotonic decrease in the concentration of carbon with increasing take-off angle suggests that a contaminat-

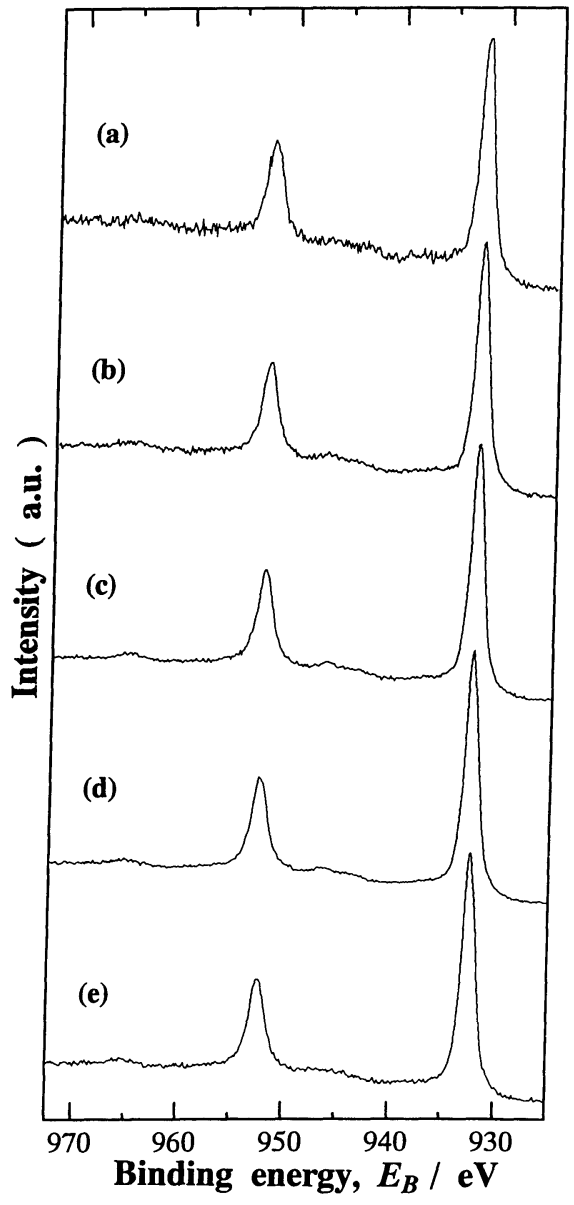

Fig. $3 \mathrm{Cu} 2 \mathrm{p}$ AR-XPS spectra obtained in the take-off angle of (a) $0.262 \mathrm{rad}$, (b) $0.524 \mathrm{rad}$, (c) $0.786 \mathrm{rad}$, (d) $1.05 \mathrm{rad}$ and (e) $1.31 \mathrm{rad}$ for ultra high-purity copper exposed to air for $1.8 \times 10^{3} \mathrm{~s}$.

ed layer of hydrocarbon covers the specimens. It is also cited in Fig. 6 that take-off angle dependence of the concentration of oxygen indicates an oxide layer between the overlayer and the matrix. On the other hand, the increase in the $\mathrm{Fe} 2 \mathrm{p}$ concentration with increasing take-off angle may be attributed to the formation of both oxide layer and overlayer. With long term exposure to air, the concentration of contaminated carbon increases, but a change in the oxygen concentration is not so significant. The lines in Figs. 6(a) and (b) denote the concentrations for carbon, oxygen, and iron, calculated from the model of layered structure. The calculation agrees well with the experimental data and thus the model of layered structure is considerably acceptable.

On the other hand, the results for ultra high-purity copper exposed to air under the identical condition are shown in Fig. 7. Although the take-off angle dependence of the concentration of carbon, oxygen and copper is rather similar to the results of ultra high-purity iron, the following characteristic variation due to time difference of air exposure may be stressed for ultra high-purity copper. The copper concentration is dominant in the specimen exposed to air for $1.8 \times 10^{3} \mathrm{~s}$, independent of take-off angle. However, the copper concentration con- 


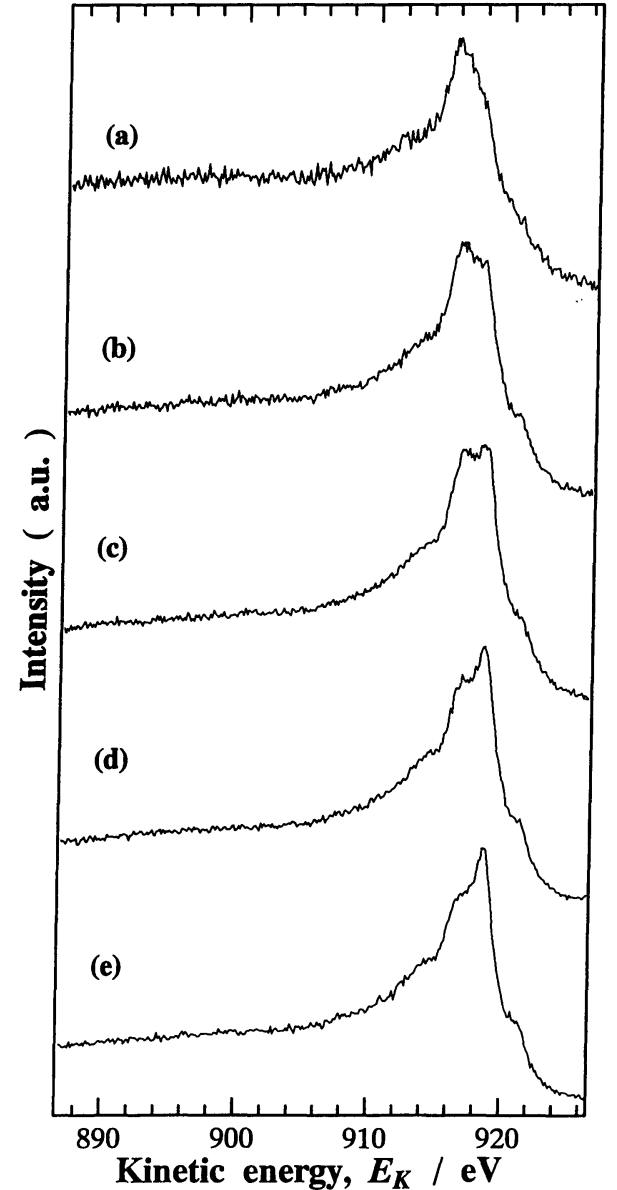

Fig. $4 \mathrm{Cu} \mathrm{L}{ }_{3} \mathrm{M}_{45} \mathrm{M}_{45}$ AR-XAES spectra obtained in the take-off angle of (a) $0.262 \mathrm{rad}$, (b) $0.524 \mathrm{rad}$, (c) $0.786 \mathrm{rad}$, (d) $1.05 \mathrm{rad}$ and (e) 1.31 $\mathrm{rad}$ for ultra high-purity copper exposed to air for $1.8 \times 10^{3} \mathrm{~s}$.

siderably decreases in the specimen exposed for $4.2 \times 10^{5}$ $\mathrm{s}$. This clearly suggests that thick oxide layer forms on the surface of ultra high-purity copper when applied to long exposure time.

The values of thickness of oxide layers and contaminated layers for two cases which were obtained by fitting the calculated results to the experimental ones are plotted as a function of exposure time as shown in Fig. 8. The oxide layer thickness for ultra high-purity iron is found to almost unchanged by exposure time, whereas the oxide layer in ultra high-purity copper becomes considerably thicker in the present exposure condition. These results are consistent with the facts that spectral changes by air exposure are remarkable in ultra high-purity copper, as shown in Figs. 3 and 5. In addition, the thickness of contaminated layers increases with increasing exposure time in both ultra high-purity iron and copper. Although a small difference in the thickness of contaminated layers is observed between ultra high-purity iron and copper, the total thickness of oxide layer and overlayer appears to be almost independent of substrate materials.

Based on the present results, differences of oxide layer formation and growth between ultra high-purity iron and copper may be discussed. It is interesting to note in the

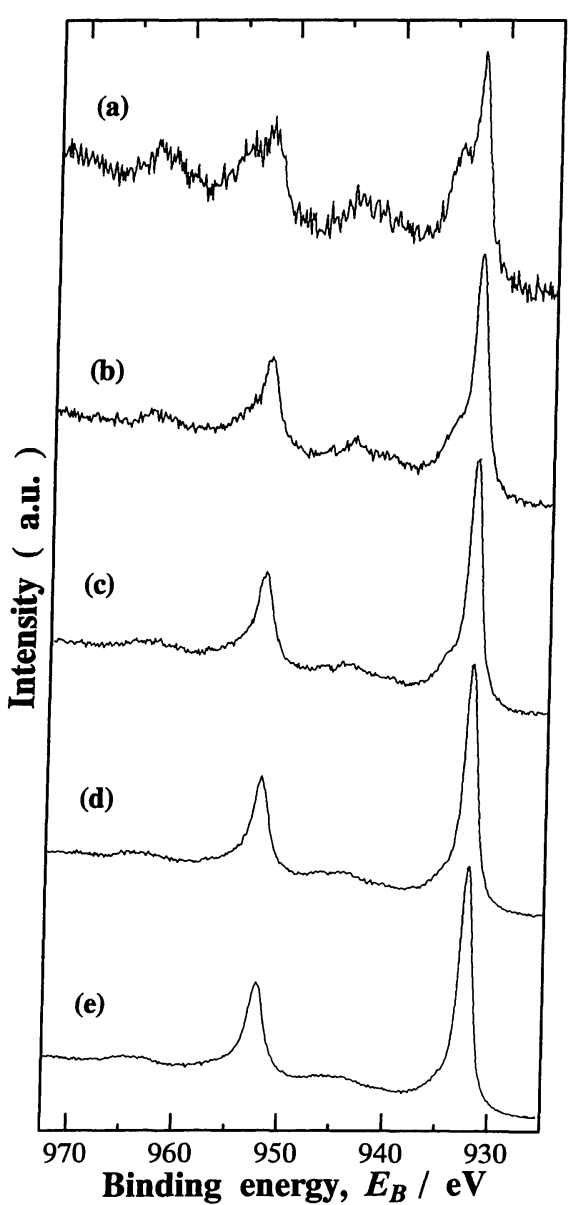

Fig. $5 \mathrm{Cu} 2 \mathrm{p}$ AR-XPS spectra obtained in the take-off angle of (a) $0.262 \mathrm{rad}$, (b) $0.524 \mathrm{rad}$, (c) $0.786 \mathrm{rad}$, (d) $1.05 \mathrm{rad}$ and (e) $1.31 \mathrm{rad}$ for ultra high-purity copper exposed to air for $4.2 \times 10^{5} \mathrm{~s}$.

results of Fig. 8 that the oxide layer thickness for ultra high-purity iron is thicker than that for ultra high-purity copper in short term exposure. This suggests that an oxide layer is easily formed on the surface of ultra highpurity iron, comparing to ultra high-purity copper. On the other hand, the growth behavior of the oxide layer appears to be different from its formation, as indicated by a small exposure time dependence of the thickness of an oxide layer. The growth rate of an oxide layer, which may correspond to an increase in the oxide layer thickness, is considered to be affected by characteristic mobilities of anions and cations in the oxide layer. Therefore, slow growth of an oxide layer in ultra high-purity iron could be attributed to low mobility of the constituent ions in the oxide layer at room temperature, while higher mobilities of constituent ions in an oxide layer of ultra high-purity copper are quite likely to induce a relatively rapid increase of the oxide layer thickness, as shown in Fig. 8.

Finally, let us consider a possibility for non-destructive analysis of a specimen surface layer, taking into account the analyzed position. In the present work, the surfaces of a pair of ultra high-purity iron and copper plates exposed to air under given conditions have been character- 


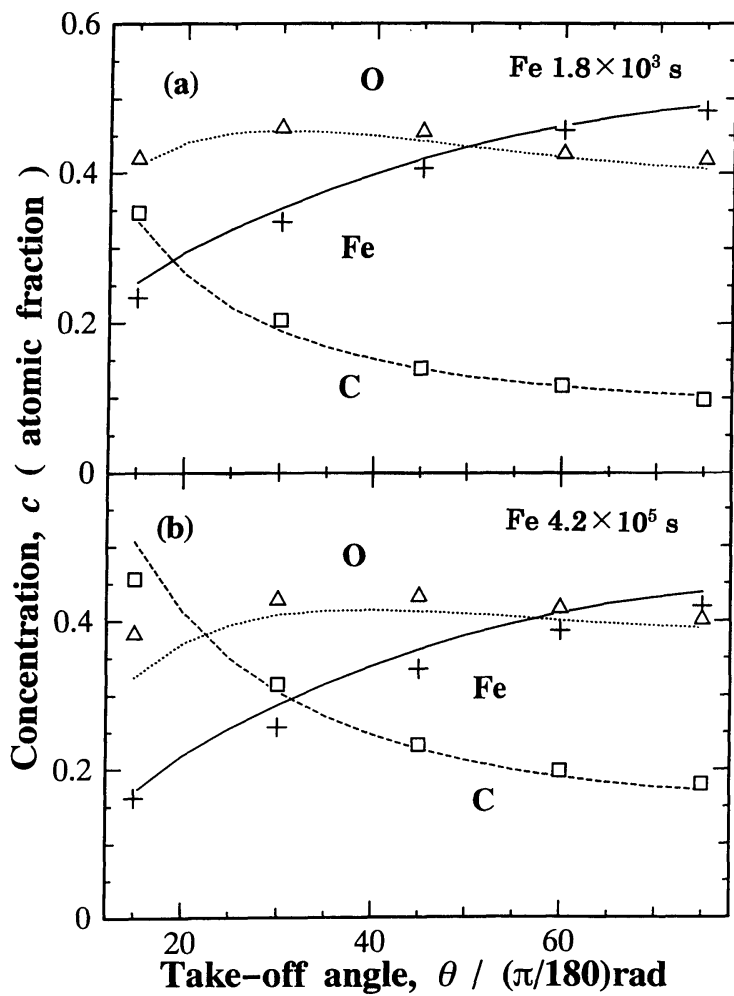

Fig. 6 The concentration of iron, oxygen and carbon versus the takeoff angle in ultra high-purity iron specimens which are exposed to air for (a) $1.8 \times 10^{3} \mathrm{~s}$ and (b) $4.2 \times 10^{5} \mathrm{~s}$. Experimental and calculated results are denoted by marks and lines, respectively.

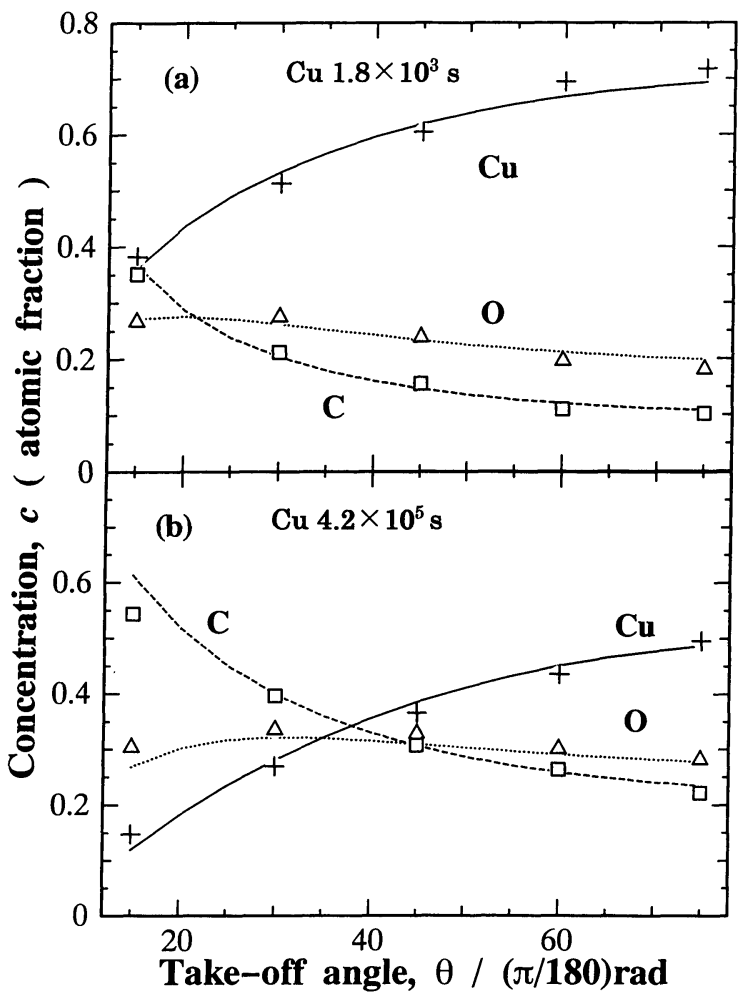

Fig. 7 The concentration of copper, oxygen and carbon versus the take-off angle in ultra high-purity copper specimens which are exposed to air for (a) $1.8 \times 10^{3} \mathrm{~s}$ and (b) $4.2 \times 10^{5} \mathrm{~s}$. Experimental and calculated results are denoted by marks and lines, respectively.

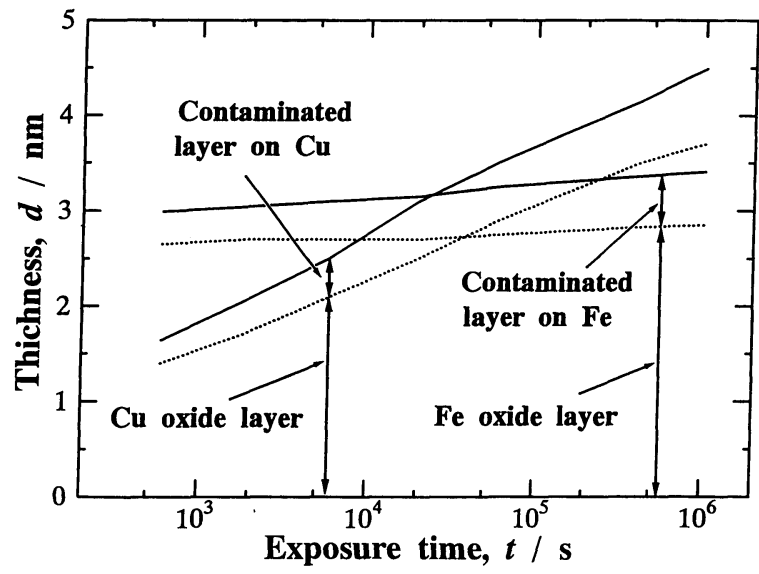

Fig. 8 Thickness of oxide layer and contaminated layer formed on the surface of ultra high-purity iron and copper as a function of air exposure time.

ized by AR-XPS, and different layered structures on the specimen surface are found for these two metals. In other words, the present method enables us to realize simple tomography of constituent elements in a layered structure of thickness of nanometer order of magnitude for surface of metallic materials, as exemplified by the results of Fig. 8. It is expected in the surface of a specimen consisting of multi-phases that different surface reactions may take place in different phases. Therefore, although analyzed area is limited in a specimen, microstructural tomography concerning the elemental composition and chemical state in a surface layer can be made by extending the present method to small area analysis. Such information on the layered structures in the specimen surface may be very effective for interpreting various surface phenomena of variety of metallic materials.

\section{Concluding Remarks}

Angle resolved X-ray photoelectron spectroscopy (ARXPS) has been used for investigating native oxide layers formed on the surface of ultra high-purity iron and copper by exposure to air at room temperature. The main results are as follows:

(1) The chemical state of $\mathrm{Fe}$ on the oxidized surface of ultra high-purity iron by air exposure is almost independent of exposure time. On the other hand, the chemical state of oxidized copper on the surface of ultra high-purity copper is changed by exposure time; $\mathrm{Cu}^{2+}$ appears with long-term exposure other than $\mathrm{Cu}^{1+}$ which formed in the initial stage.

(2) Thickness of an oxide layer formed on the surface of ultra high-purity iron found to be thicker than that for ultra high-purity copper in the initial stage. However, an increase in the oxide layer thickness on the surface of ultra high-purity iron with exposure time is insignificant, while the oxide layer thickness on ultra high-purity copper is found to depend upon time for exposure to air.

(3) The thickness of contaminated layer increases with increasing exposure time, which seems to be indepen- 
dent of substrate materials.

It would be also interesting from the present results to extend the AR-XPS method to the characterization of systematic changes in thickness of surface layers formed on a variety of metallic materials by exposure.

\section{Acknowledgments}

The authors are grateful to Mr. T. Sato and Mr. M. Itoh for their help in operation and maintenance of XPS apparatus.

\section{REFERENCES}

(1) M. Isshiki and K. Igaki: Trans. JIM, 18 (1977), 412.

(2) K. Sugimoto, S. Matsuda, M. Isshiki, T. Ejima and K. Igaki: J. Japan Inst. Metals, 46 (1982), 155.

(3) K. Miyake, K. Ohashi, H. Takahashi and T. Minemura: Surf. Coat. Technol., 65 (1994), 208.

(4) Y. Ishikawa, K. Mimura and M. Isshiki: Bull. Inst. Adv. Mater. Process., 51 (1995), 10
(5) A. Tanaka, R. Oiwa, T. Daichoh and K. Abiko: Ultra High Purity Base Metals (UHPM-94), ed. by K. Abiko, K. Hirokawa and S. Takaki, Japan Inst. Metals, Sendai, (1995), p. 436.

(6) C. R. Brunlde: Surf. Sci., 66 (1977), 581.

(7) F. Gronlund and P. E. H. Nielsen: Surf. Sci., 30 (1972), 388.

(8) S. S. Fu and G. A. Somorjai: Surf. Sci., 262 (1992), 68.

(9) S. Suzuki, T. Kosaka, H. Inoue and Y. Waseda: Mater. Trans., JIM, 36 (1995), 1379.

(10) S. Suzuki, T. Kosaka, H. Inoue and Y. Waseda: ISIJ International, 36 (1996), 433.

(11) S. Suzuki, T. Nakazawa and Y. Waseda: ISIJ International, 36 (1996), 1273.

(12) S. Poulston, P. M. Parlett, P. Stone and M. Bowker: Surf. Interface Anal., 24 (1996), 811.

(13) S. Tanuma, C. J. Powell and D. R. Penn: Surf. Interface Anal., 11 (1988), 577.

(14) S. Tanuma, C. J. Powell and D. R. Penn: Surf. Interface Anal., 17 (1991), 911.

(15) J. F. Moudler, W. F. Stickle, P. E. Sobol and K. Bomben: $X$-ray photoelectron spectroscopy, Physical Electronics, Minnesota, (1993), p. 219. 